\title{
Makna Pemanfaatan Hijab dalam Iklan Produk Shampo Versi Berjilbab di Televisi
}

\author{
${ }^{1}$ Alfia Zain, ${ }^{2}$ Fatmawati \\ ${ }^{1,2}$ Fakultas Ilmu Dakwah dan Komunikasi, UIN Syarif Hidayatullah Jakarta \\ Email: ${ }^{1}$ alfia8350@gmail.com, ${ }^{2}$ fatmawati@uinjkt.ac.id
}

\begin{abstract}
Abstrak. Penelitian ini bertujuan untuk mengetahui makna pemanfaatan hijab terhadap keindahan rambut wanita yang terdapat dalam iklan produk Sunsilk Clean And Fresh di televisi, dengan menggunakan model analisis semiotika Charles Sanders Peirce. Penelitian ini menggunakan pendekatan kualitatif dengan metode deskriptif analisis, serta paradigma konstruktivis. Teknik pengumpulan data yang digunakan adalah observasi dengan mengamati tayangan iklan Sunsilk Clean And Fresh, wawancara dengan informan terkait, dan dokumentasi. Hasil dari penelitian ini menemukan bahwa iklan dalam produk Shampo Sunsilk Clean And Fresh menggambarkan kenyamanan dan kesegaran rambut seorang wanita yang menggunakan hijab sepanjang hari dengan melakukan aktivitas yang padat. Makna yang terkandung dalam iklan ini sesuai dengan model semiotika Charles Sanders Peirce. Kemudian, pemanfaatan hijab dari iklan akhirnya menimbulkan kontrovesi pada pribadi seseorang, masyarakat dan lingkungan sosial. Makna hijab sebagai identitas Muslimah dimanfaatkan dalam iklan sebagai media komersial yang mengaburkan tujuan dari tujuan pengguna hijab itu sendiri.
\end{abstract}

Kata kunci: televisi, wanita, iklan produk Sunsilk Clean and Fresh, semiotika Charles Sanders Peirce, makna pemanfaatan, hijab.

\begin{abstract}
This study aims to determine the meaning of the use of hijab to the beauty of women's hair contained in Sunsilk Clean And Fresh product ads on television using Charles Sanders Peirce's semiotic analysis model. This research uses qualitative approach with descriptive method of analysis, and constructivist paradigm. Data collection techniques used were observations by observing Sunsilk Clean And Fresh advertisements, interviews with related informants, and documentation. The results of this study found that ad in Shampo Sunsilk Clean and Fresh products describes the comfort and freshness of a woman's hair that uses hijab throughout the day by performing a dense activity. The meaning contained in this ad corresponds to Charles Sanders Peirce's semiotic model. Then, the use of veils from advertising ultimately leads to controversy in a person, society and social environment. The meaning of hijab as a Muslim identity is utilized in advertising as a commercial medium that obscures the purpose of the hijab user themselves.
\end{abstract}

Keywords : television, women, product ads Sunsilk Clean and Fresh, semiotics Charles Sander Peirce, meaning of utilization, hijab. 


\section{PENDAHULUAN}

Media massa sudah menjadi bagian tak terpisahkan dari komunikasi manusia. Media massa kini telah menjadi salah satu alat penyampaian pesan atau informasi kepada masyarakat karena melibatkan penerima pesan dalam jumlah banyak serta tersebar dalam area geografis yang luas, namun mempunyai perhatian minat dan isu yang sama. Media elektronik seperti televisi merupakan media paling dominan dalam penyampaian pesan karena televisi adalah media komunikasi yang bersifat dengar-lihat (audio-visual). Selain itu, dampak pemberitaan melalui televisi bersifat power full melibatkan aspek suara dan gambar sehingga lebih memberi pengaruh yang kuat kepada pemirsanya (Suryawati, 2011).

Saat ini, televisi merupakan media untuk melakukan aktivitas dakwah. Kemajuan zaman dan teknologi mengharuskan kegiatan dakwah bukan lagi hanya dilakukan melalui media mimbar. Dengan demikian, melalui media televisi mampu diakses oleh banyak pihak dalam waktu serempak serta media televisi memang dekat dengan masyarakat. Salah satu aktivitas dakwah dengan media televisi adalah dengan menyajikan program religi ataupun iklan yang menyajikan atau menyampaikan pesan dakwah (Khairiyah, 2013).

Saat ini, banyak iklan yang memanfaatkan tren dari hijab terutama iklan kosmetik, selain ada pula iklan shampo yang biasa kita lihat sebagai bentuk keindahan rambut dari wanita, kini iklannya pun ada yang memakai hijab. Jilbab itu sendiri adalah pakaian seorang Muslimah yang menutupi bagian-bagian aurat kaum wanita. Islam mewajibkan kaum wanita untuk berhijab karena memiliki banyak manfaat, seperti untuk memuliakan kaum wanita, untuk kesehatan, dan kecantikan. Selain itu, kewajiban menutup aurat ditujukan untuk menjaga kehormatan. Kemudian, dampak dari jilbab adalah untuk memperkenalkan manusia pada kecantikan dan keindahan yang sejati. Karena kecantikan dan keindahan fisik bukanlah modal utama, maka inner beauty-lah yang membuat perempuan terlihat sempurna. Eksploitasi kecantikan dan keindahan fisik pada akhirnya menimbulkan kontroversi pada pribadi seseorang dan lingkungan sosial (Jayanti, 2014).

Sebelumnya, Ahmadi dan Yohana (2005) mengemukakan bahwa jilbab yang dikenakan dengan berbagai gaya memiliki beragam motif. Pertama, sebagai motif teologis yaitu bentuk kepatuhan pada kewajiban agama. Kedua, sebagai motif psikologis yang dinyatakan dengan kenyamanan sebagai alasan menggunakan jilbab. Ketiga, sebagai motif modis, yaitu bentuk ketanggapan atas perkembangan fashion Islami di tanah air.

Penelitian ini menggunakan analisis semiotika yang merupakan sebuah ikhtiar untuk merasakan sesuatu yang aneh, sesuatu yang dipertanyakan lebih lanjut ketika kita membaca teks atau narasi/wacana tertentu. Analisisnya bersifat paradigmatic dalam arti berupaya menemukan makna, termasuk dari hal-hal yang tersembunyi di balik sebuah teks. Di dalam lingkup semiotika Peirce, sebagaimana dipaparkan Lechte, seringkali mengulang-ngulang bahwa secara umum tanda adalah yang mewakili sesuatu bagi seseorang. Bagi Peirce, tanda "is something which stands to somebody for something in some respect or capacity".

Berdasarkan objeknya, Peirce membagi tanda atas icon (ikon), index (indeks), dan symbol (simbol). Ikon adalah tanda yang hubungan antara penanda dan petandanya bersifat bersamaan bentuk alamiah. Atau dengan kata lain, ikon adalah hubungan antara tanda dan objek atau acuan yang bersifat kemiripan Misalnya, potret dan peta. 
Alfia Zain, dkk. Makna Pemanfaatan Hijab dalam Iklan Produk Shampo...

TABEL 1. Semiotika Peirce

\begin{tabular}{llll}
\hline Jenis Tanda & \multicolumn{1}{c}{ Ditandai dengan } & \multicolumn{1}{c}{ Contoh } & Proses Kerja \\
\hline Ikon & $\begin{array}{l}\text {-persamaan } \\
\text {-kemiripan }\end{array}$ & Gambar, foto, dan patung & Dilihat \\
Indeks & $\begin{array}{l}\text {-hubungan sebab-akibat } \\
\text {-keterkaitan }\end{array}$ & $\begin{array}{l}\text { - asap-api } \\
\text { - gejala-penyakit }\end{array}$ & Diperkirakan \\
& -konvensi atau & - kata-kata & Dipelajari \\
Simbol & kesepakatan sosial & - isyarat & \\
\hline
\end{tabular}

Indeks adalah tanda yang menunjukkan adanya hubungan alamiah antara tanda dan petanda yang bersifat kausal atau hubungan sebab-akibat, atau petanda yang langsung mengacu pada kenyataan. Simbol adalah tanda yang menunjukkan hubungan alamiah antara tanda dengan petandanya (Sobur, 2009).

Semiotika memiliki tiga wilayah kajian, yaitu (1) Tanda. Wilayah ini meliputi kajian mengenai jenis tanda yang berbeda, cara-cara berbeda dari tandatanda di dalam menghasilkan makna, dan cara tanda tersebut berhubungan dengan orang yang menggunakannya. (2) Kodekode, atau sistem di mana tanda-tanda diorganisasi. (3) Budaya, tempat di mana tanda-tanda diorganisasi.

Teori Peirce seringkali disebut sebagai "grand theory" dalam semiotika karena, gagasan Peirce bersifat menyeluruh, deskripsi struktural dari semua sistem penandaan. Peirce ingin mengidentifikasi partikel dasar dari tanda dan menggabungkan kembali semua komponen dalam struktur tunggal. Sebuah tanda atau representamen, menurut Charles S Peirce, adalah sesuatu yang bagi seseorang mewakili sesuatu yang lain dalam beberapa hal atau kapasitas.

Sesuatu yang lain oleh Peirce disebut interpretant dinamakan sebagai interpretan dari tanda yang pertama, pada gilirannya akan mengacu pada objek tertentu. Dengan demikian, menurut Peirce, sebuah tanda atau representamen memiliki relasi "triadik" langsung dengan interpretan dan objeknya. Apa yang dimaksud dengan proses yang memadukan entitas (berupa representamen) dengan entitas lain yang disebut sebagai objek. Proses ini, Peirce sebut sebagai signifikasi (Wibowo, 2013).

\section{METODE}

Penelitian ini menggunakan paradigma kosntruktivisme yang menganggap komunikan bersifat aktif. Komunikan merupakan makhluk hidup yang memiliki akal dan pikiran dalam menentukan sikap, sehingga apabila seseorang menyampaikan pesan kepada orang lain, pesan yang diterima oleh orang tersebut akan dimaknai berbeda. Pandangan konstruktivisme melihat realitas merupakan hasil bentukan manusia; realitas adalah bentuk penafsiran manusia. Realitas ada di dalam pikiran manusia, bukan di luar pikiran manusia, sehingga disebut realitas subjektif. Dalam kajian media, konstruktivis tidak melihat media hanya sebagai alat penyampaian pesan. Media bukan cermin yang merefleksikan peristiwa begitu saja, sehingga apa yang kita lihat di media merupakan realitas yang dibentuk. Realitas hasil bentukan ini dibuat sedemikian rupa agar khalayak meyakini kebenaran (Verdiansyah, 2008).

Dalam penelitian ini, penulis menggunakan pendekatan penelitian kualitatif. Penelitian kualitatif ialah sebagai prosedur penelitian dengan tujuan menghasilkan data deskriptif 
berupa kata-kata tertulis maupun lisan dari orang-orang dan perilaku yang dapat diamati (Moloeng, 2005), yaitu dengan metode wawancara mendalam, observasi partisipasi, serta dokumentasi. Adapun tempat penelitiannya adalah PT Unilever, Tbk. waktu penelitiannya dari 5 September 2015 s.d. 28 Oktober 2015. Subjek penelitian adalah PH (production house) sunsilk clean and fresh. Sedangkan objeknya adalah iklan sunsilk clean and fresh versi berjilbab.

Pada penelitian ini, peneliti menggunakkan model semiotika Charles Sanders Peirce. Dalam teorinya, Peirce membagi tanda ke dalam tiga elemen utama yang disebut dengan teori segitiga mana (triagle meaning). Pertama, objek yaitu konteks sosial yang menjadi referensi dari tanda-tanda yang dirujuk tanda (Kriyanto, 2007). Kedua, interpretan, yaitu setiap tanda yang dipahami oleh seseorang dalam membangkitkan atau berasosiasi dengan tanda lain di dalam benaknya. Dan ketiga, representmen, yaitu sesuatu yang bersifat inderawi atau material yang berfungsi sebagai tanda. Dari sudut pandang Charles Peirce ini, proses signifikansi bisa saja menghasilkan rangkaian hubungan yang tidak berkesudahan, sehingga pada gilirannya sebuah interpretan akan menjadi representamen, menjadi interpretan lagi, jadi representamen lagi (Wibowo, 2013).

Dalam memahami kredibilitas (derajat kepercayaan), suatu keabsahan data dapat ditempuh dengan menggunakan teknik triangulasi. Triangulasi adalah teknik pemeriksaan keabsahan data yang memanfaatkan sesuatu yang lain di luar data itu untuk keperluan pengecekan atau sebagai pembanding terhadap data itu (Moleong, 2000). Triangulasi dengan sumber berarti membandingkan dan mengecek balik derajat kepercayaan suatu informasi yang diperoleh melalui waktu dan alat yang berbeda dalam metode kualitatif. Hal tersebut dapat diperoleh dengan cara, yaitu membandingkan data hasil pengamatan dengan data hasil wawancara, dan membandingkan hasil wawancara dengan isi suatu dokumen yang berkaitan.

\section{HASIL DAN PEMBAHASAN}

Analisis Semiotika Iklan Produk Shampo Sunsilk Clean And Fresh Versi Berjilbab di Televisi

\section{(1) Scene 1}

Pada scene ini seorang wanita yang menggunakan busana tertutup dan menggunakan inner hijab, sedang berjalan menuju ruangan seraya tersenyum penuh kelembutan, di sebelah kanannya terdapat cermin yang memperlihatkan wajah dan senyuman wanita tersebut. Diperkuat dengan ucapan sang narator yang mengatakan "sekarang rambutku tertutup hijab sepanjang hari."

Hasil wawancara dengan Tiara Putri Selaku Assistant Brand Manager Sunsilk pada 28 Oktober 2015 melalui email: "Rambut yang tertutup hijab sepanjang hari dapat membuat ketidaknyamanan karena kulit kepala mengalami keringat yang berlebih. Dengan selalu menjaga

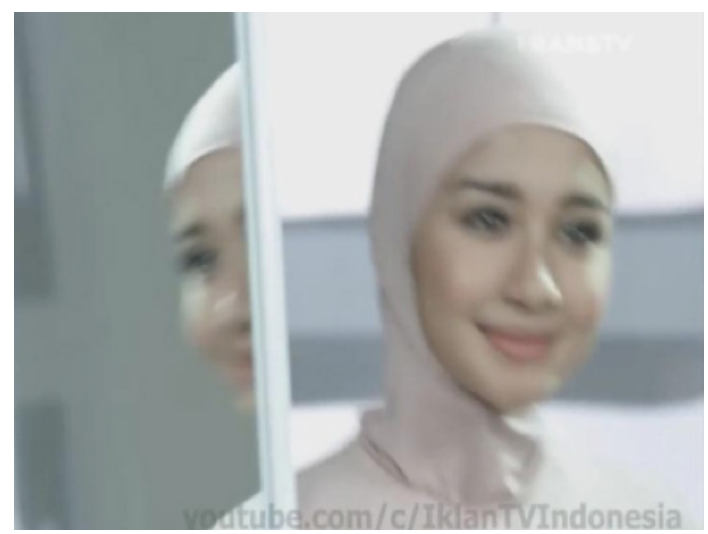

GAMBAR 1. Seorang Wanita Sedang Berada dalam Ruangan

kebersihan dan kesehatan rambut dan kulit kepala, rambut akan terasa bersih dan segar sepanjang hari."

Dari hasil wawancara, pada dasarnya rambut adalah mahkota dari 
Alfia Zain, dkk. Makna Pemanfaatan Hijab dalam Iklan Produk Shampo...

TABEL 2. Wanita Sedang Berjalan menuju Ruangan

\begin{tabular}{|l|l|}
\hline \multicolumn{1}{|c|}{ Tipe Tanda } & \multicolumn{1}{|c|}{ Data } \\
\hline Representamen (X) & $\begin{array}{l}\text { Terlihat seorang wanita yang mengenakan inner jilbab sedang } \\
\text { berjalan menuju suatu ruangan tepat di sebelah kiri wanita itu terlihat } \\
\text { ada cermin. }\end{array}$ \\
\hline Indeks & $\begin{array}{l}\text { Indeks pada adegan ini ditampilkan melalui gambar seorang } \\
\text { wanita dengan menggunakan inner jilbab berwarna pink atau merah } \\
\text { muda identik dengan warna yang menggambarkan keanggunan } \\
\text { seorang wanita. Cermin yang terdapat di sebelah wanita tersebut } \\
\text { memperlihatkan wajah seorang wanita yang sedang berjalan menuju } \\
\text { ruangan. }\end{array}$ \\
\hline Simbol & $\begin{array}{l}\text { - Tanda verbalnya "sekarang rambutku tertutup hijab sepanjang hari" } \\
\text { mengurangi keindahan pada rambut seorang wanita Muslimah. }\end{array}$ \\
\hline
\end{tabular}

TABEL 2.1 Makna Wanita Sedang Berjalan menuju Ruangan

\begin{tabular}{|l|l|}
\hline Objek $(\mathrm{Y})$ & Seorang wanita berbusana Muslimah dengan menggunakan inner hijab. \\
\hline Interpretan $(\mathrm{X}=\mathrm{Y})$ & Seorang wanita dengan ketenangan dan kelembutan hati. \\
\hline Makna & $\begin{array}{l}\text { Kecantikan dan ketenangan hati akan menjadikan jiwa seseorang } \\
\text { menjadi nyaman dan tenang, terlihat dari senyuman yang terpancar dari } \\
\text { wajahnya seolah menggambarkan hati dan pikirannya. }\end{array}$ \\
\hline
\end{tabular}

Sumber: Data Primer

wanita yang harus terjaga kebersihannya. Keindahan adalah suatu kecantikan yang terdapat pada setiap wanita. Kecantikan hakiki dan ideal adalah kecantikan yang bersumber dari dimensi ilahiah (hati).

Berdasarkan Tabel 2, yang merupakan representamen (X) ikon adalah wanita yang mengenakan inner jilbab. Indeks digambarkan dengan seorang wanita dengan menggunakan inner jilbab berwarna merah muda yang menggambarkan keanggunan seorang wanita. Sedangkan simbol digambarkan berupa tanda verbal "sekarang rambutku tertutup hijab sepanjang hari."

Objek dalam scene pada Gambar 1 adalah seorang wanita berbusana Muslimah dengan menggunakan inner hijab, interpretan $(\mathrm{X}=\mathrm{Y})$ adalah seorang wanita dengan ketenangan dan kelembutan hati dan maknanya adalah kecantikan dan ketenangan hati akan menjadikan jiwa seseorang menjadi nyaman dan tenang.

\section{(2) Scene 2}

Pada scene ini terlihat seorang wanita yang sedang meraih satu jilbab yang berwarna abu-abu dari enam jilbab yang ada di depannya. Tayangan ini ingin memperlihatkan tangan sosok wanita yang mengambil jilbab tersebut untuk digunakan agar dapat melengkapi busananya yang sudah tertutup dengan baju Muslimah dan inner. Hal ini dapat dilihat dari gerak gerik tubuh yang

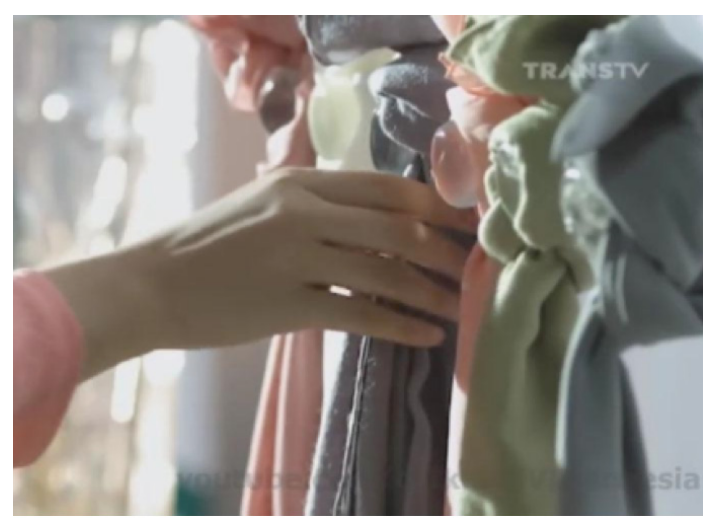

GAMBAR 2. Tangan Seorang Wanita tengah Mengambil Jilbab 
TABEL 3. Tangan Seorang Wanita sedang Mengambil Jilbab

\begin{tabular}{|l|l|}
\hline \multicolumn{1}{|c|}{ Tipe Tanda } & \multicolumn{1}{c|}{ Data } \\
\hline Representamen $(\mathrm{X})$ & $\begin{array}{l}\text { Seorang wanita berbusanan Muslimah tengah mengambil jilbab di } \\
\text { dalam suatu ruangan. }\end{array}$ \\
\hline Indeks $(\mathrm{Jilbab})$ & $\begin{array}{l}\text { Adegan tangan seorang wanita tengah mengambil sebuah jilbab } \\
\text { dan mengarahkan tangannya ke jilbab yang berwarna abu-abu. }\end{array}$ \\
\hline Simbol & $\begin{array}{l}\text { Simbol yang muncul adalah tangan seorang wanita yang tengah } \\
\text { berusaha meraih sebuah jilbab yang akan ia kenakan. }\end{array}$ \\
\hline
\end{tabular}

TABEL 3.1 Makna Tangan Seorang Wanita sedang Mengambil Jilbab

\begin{tabular}{|l|l|}
\hline Objek $(\mathrm{Y})$ & Wanita sedang memilih jilbab \\
\hline $\begin{array}{l}\text { Interpretan } \\
(\mathrm{X}=\mathrm{Y})\end{array}$ & $\begin{array}{l}\text { Wanita tersebut ingin melengkapi busananya dengan mengenakan hijab } \\
\text { berwarna abu-abu }\end{array}$ \\
\hline Makna & $\begin{array}{l}\text { Gambaran seorang wanita Muslimah yang anggun dengan menutup aurat } \\
\text { dan mahkotanya dengan jilbab }\end{array}$ \\
\hline
\end{tabular}

Sumber: Data Primer

diperagakan oleh model.

Berdasarkan Tabel 3, yang merupakan representamen (X) ikon (jilbab) adalah Seorang wanita berbusana Muslimah sedang mengambil jilbab di dalam suatu ruangan. Indeks digambarkan dengan adegan tangan seorang wanita sedang mengambil sebuah jilbab dan mengarahkan tangannya ke jilbab yang berwarna abu-abu. Simbolnya adalah tangan yang berusaha meraih jilbab yang akan dikenakan.

Objek dalam scene pada Gambar 2 adalah wanita sedang memilih jilbab, interpretan $(\mathrm{X}=\mathrm{Y})$ adalah wanita tersebut ingin melengkapi busananya dengan mengenakan hijab berwarna abu-abu dan maknanya adalah seorang wanita Muslimah yang anggun dengan menutup aurat dan mahkotanya dengan jilbab.

\section{(3) Scene 3}

Pada scene ini seorang wanita Muslimah yang tengah memakai jilbab di depan cermin di dalam ruangan kamarnya sambil terus tersenyum. Adegan diperkuat dengan tangan wanita tersebut mengangkat ke arah depan samping wajahnya. Ia tampak teliti dalam mengenakan jilbab yang pada tanyangan sebelumnya telah dipilih. Dengan baju berwarna merah muda, celana dan jilbab berwarna abu-abu tangan wanita tersebut berusaha untuk tetap merapikan jilbab yang ia pakai, agar terlihat rapi.

Dalam scene ini wanita tersebut tampak anggun. Scene ini ingin menggambarkan bahwa untuk terlihat cantik bisa dilakukan dengan cara yang sederhana tanpa harus mengorbankan banyak uang, waktu, dan tenaga. Cara sederhana yang bisa dilakukan adalah dengan tersenyum. Terdapat teori yang mengatakan bahwa wajah mencerminkan jiwa, dan bahwa kecantikan dan kebaikan

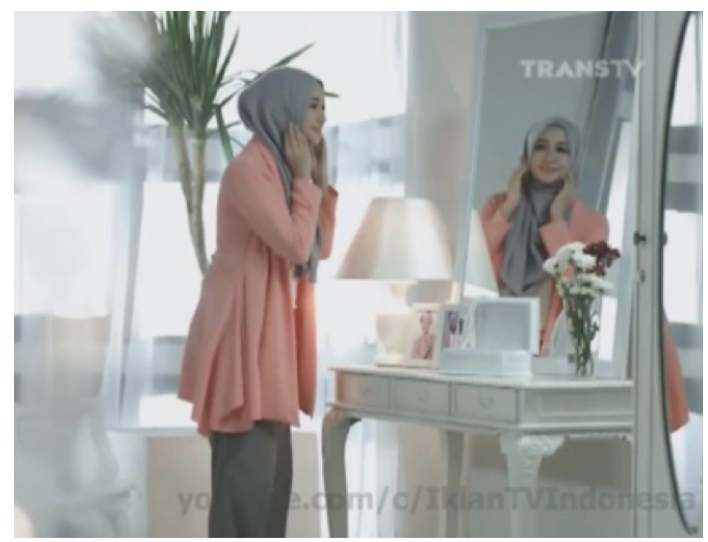

GAMBAR 3. Seorang Wanita yang tengah Bercermin 
Alfia Zain, dkk. Makna Pemanfaatan Hijab dalam Iklan Produk Shampo...

TABEL 4. Wanita Sedang Bercermin di dalam Ruangan

\begin{tabular}{|l|l|}
\hline \multicolumn{1}{|c|}{ Tipe Tanda } & \multicolumn{1}{c|}{ Data } \\
\hline $\begin{array}{l}\text { Representamen (X) } \\
\text { Ikon }\end{array}$ & $\begin{array}{l}\text { Terlihat seorang wanita berbusana Muslimah sedang memakai } \\
\text { jilbab yang ada di dalam ruangan tepat didepan wanita tersebut } \\
\text { berdiri ada cermin yang memperlihatkan wajah wanita itu sedang } \\
\text { mengenakan jilbab. }\end{array}$ \\
\hline Indeks & $\begin{array}{l}\text { Sosok wanita dengan baju tertutup identik dengan seorang } \\
\text { Muslimah yang sedang mengenakan jilbab yang sudah ia pilih } \\
\text { untuk dikenakan. }\end{array}$ \\
\hline Simbol & $\begin{array}{l}\text { Tanda nonverbal ditempat wanita tersebut berdiri terdapat cermin } \\
\text { yang ia gunakan dan lampu yang menghias ruangan tersebut. }\end{array}$ \\
\hline
\end{tabular}

TABEL 4.1 Makna Wanita Sedang Bercermin di dalam Ruangan

\begin{tabular}{|l|l|}
\hline Objek $(\mathrm{Y})$ & Wanita berhijab \\
\hline Interpretan $(\mathrm{X}=\mathrm{Y})$ & Sosok wanita Muslimah yang salehah \\
\hline Makna & $\begin{array}{l}\text { Seorang wanita yang tidak hanya mementingkan kecantikan dan } \\
\text { keindahan fisik semata. }\end{array}$ \\
\hline
\end{tabular}

Sumber: Data Primer

adalah satu kemudian direfleksikan dalam wajah (Synnott, 2007).

Berdasarkan Tabel 4, yang merupakan representamen (X) ikon adalah wanita berbusana Muslimah sedang memakai jilbab di depan cermin. Indeks digambarkan dengan wanita dengan baju tertutup identik dengan seorang Muslimah yang sedang mengenakan jilbab yang sudah ia pilih untuk dikenakan. Sedangkan simbolnya adalah tanda nonverbal yaitu cermin yang digunakan dan lampu yang menghiasi ruangan tersebut.

Objek dalam scene pada Gambar 3 adalah wanita berhijab. Interpretan $(\mathrm{X}=\mathrm{Y})$ adalah wanita Muslimah yang salehah dan maknanya adalah wanita yang tidak hanya mementingkan kecantikan dan keindahan fisik semata.

\section{(4) Scene 4}

Scene ini memperlihatkan seorang wanita berhijab tengah berjalan di sebuah taman dengan kepala menengok ke sebelah kanan sambil memperlihatkan wajah yang sedang mencari seseorang dan diperkuat dengan background tanaman dan pepohonan yang hijau serta dilengkapi bangku dan sebuah tempat makan yang sangat ramai. Wanita tersebut tampak sabar mencari seseorang yang akan ia temui, sambil terus berjalan melewati orang-orang di sekitarnya dan tanaman-tanaman yang hijau.

Berdasarkan Tabel 5, representamen (X) ikon adalah seorang wanita Muslimah yang sedang berjalan di taman. Indeks digambarkan dengan adegan berjalan di sebuah taman sambil menengokkan kepala. Sedangkan simbolnya adalah wanita yang berjalan diperkuat dengan

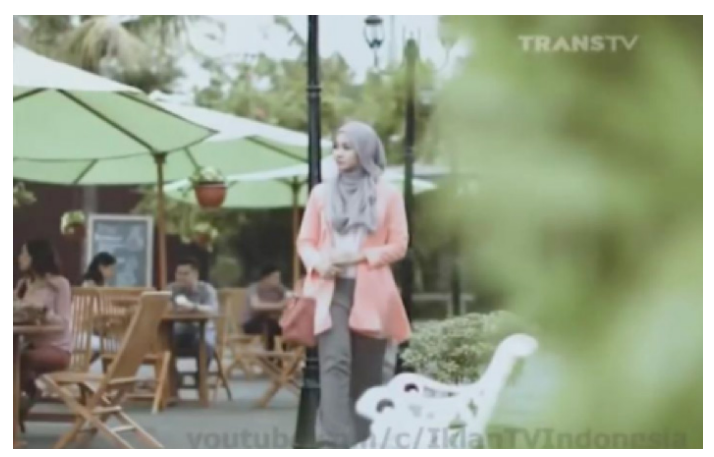

GAMBAR 4. Seorang Wanita tengah Berjalan di Taman 
TABEL 5. Wanita tengah Berjalan di Taman

\begin{tabular}{|l|l|}
\hline \multicolumn{1}{|c|}{ Tipe Tanda } & \multicolumn{1}{|c|}{ Data } \\
\hline $\begin{array}{l}\text { Representamen (X) } \\
\text { Ikon (Taman) }\end{array}$ & $\begin{array}{l}\text { Terlihat seorang wanita berbusana Muslimah sedang } \\
\text { berjalan di sebuah taman dengan menengokkan kepala } \\
\text { ke arah sebelah kanan dan diperkuat dengan background } \\
\text { tanaman yang hijau. }\end{array}$ \\
\hline Indeks & $\begin{array}{l}\text { Adegan berjalan di sebuah taman sambil menengokkan } \\
\text { kepala menjadi tanda bahwa wanita itu sedang mencari } \\
\text { seseorang. }\end{array}$ \\
\hline Simbol & $\begin{array}{l}\text { Wanita berhijab sedang berjalan di taman, adegan ini } \\
\text { diperkuat dengan suasana di sekitar ada tanaman dan } \\
\text { tempat duduk }\end{array}$ \\
\hline
\end{tabular}

TABEL 5.1 Makna Wanita tengah Berjalan di Taman

\begin{tabular}{|l|l|}
\hline Objek $(\mathrm{Y})$ & Wanita berhijab \\
\hline Interpretan $(\mathrm{X}=\mathrm{Y})$ & Sosok wanita Muslimah lengkap dengan busana tertutup \\
\hline Makna & $\begin{array}{l}\text { Seorang wanita yang berada di sebuah taman dengan berbusana } \\
\text { tertutup }\end{array}$ \\
\hline
\end{tabular}

Sumber: Data Primer

suasana di sekitar ada tanaman dan tempat duduk.

Objek dalam scene pada Gambar 4 adalah wanita berhijab, interpretan $(\mathrm{X}=\mathrm{Y})$ adalah wanita Muslimah lengkap dengan busana tertutup dan maknanya adalah wanita yang berada di sebuah taman dengan berbusana tertutup.

\section{(5) Scene 5}

Pada scene ini terlihat sosok wanita berhijab sedang menyapa kedua

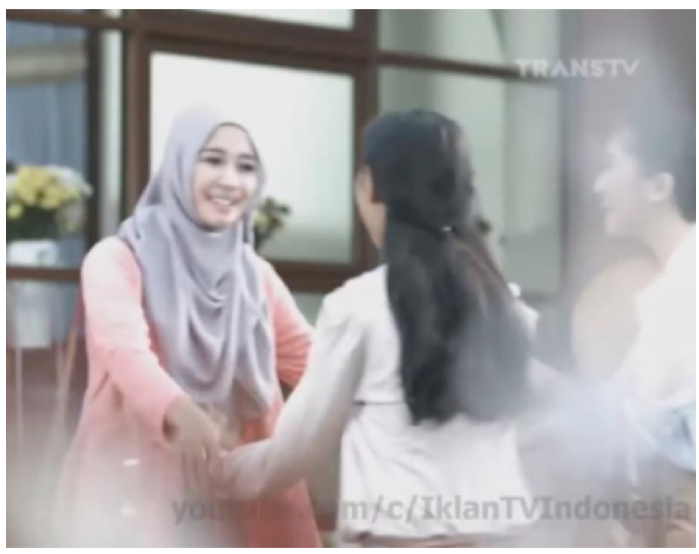

GAMBAR 5. Seorang Wanita Berhijab dengan Dua Wanita Lainnya temannya sambal menebarkan senyuman tulus. Kemudian adegan yang dilakukan dalam scene ini berupa seorang wanita berhijab yang sedang menyapa kedua temannya sambil tersenyum dengan kedua tangan yang berusaha menggapai tangan satu temannya untuk berusaha menyapa dengan akrab. Dalam Islam, tersenyum dapat dikategorikan ke dalam bentuk ibadah karena dengan memberikan senyum yang tulus kepada orang lain, maka sama halnya dengan membagi kebahagiaan. Tersenyum dapat di artikan dengan gerak bibir tersungging karena senang (Chaniago, 2000).

Berdasarkan Tabel 6, representamen (X) ikon adalah wanita berhijab dengan dua orang wanita lainnya tidak menggunakan jilbab. Indeks digambarkan dengan wanita yang tersenyum sambil merentangkan tangannya ke depan ke arah salah satu wanita, dengan maksud menyapa. Sedangkan simbolnya adalah wanita berjilbab bersama kedua temannya yang tidak menggunakan jilbab sedang berada di suatu tempat. 
Alfia Zain, dkk. Makna Pemanfaatan Hijab dalam Iklan Produk Shampo...

TABEL 6. Wanita Berhijab dengan Dua Orang Wanita Lainnya

\begin{tabular}{|l|l|}
\hline \multicolumn{1}{|c|}{ Tipe Tanda } & \multicolumn{1}{c|}{ Data } \\
\hline $\begin{array}{l}\text { Representamen }(\mathrm{X}) \\
\text { Ikon }\end{array}$ & $\begin{array}{l}\text { Seorang wanita berhijab dengan dua orang wanita lainnya tidak } \\
\text { menggunakan jilbab sedang berada di sebuah restauran. }\end{array}$ \\
\hline Indeks & $\begin{array}{l}\text { Wanita yang tersenyum sambil merentangkan tangannya ke depan ke } \\
\text { arah salah satu wanita, dengan maksud menyapa. Ini menunjukkan } \\
\text { bahwa wanita tersebut memiliki pribadi yang amah dan lembut. }\end{array}$ \\
\hline Simbol & $\begin{array}{l}\text { Wanita berjilbab dengan busana tertutup berwarna merah muda } \\
\text { dan balutan jilbab warna abu-abu bersama kedua temannya } \\
\text { yang tidak menggunakan jilbab sedang berada di suatu tempat } \\
\text { tepat di belakang wanita berjilbab terlihat sebuah jendela dan } \\
\text { vas bunga. }\end{array}$ \\
\hline
\end{tabular}

TABEL 6.1 Makna Wanita Berhijab dengan Dua Orang Wanita Lainnya

\begin{tabular}{|l|l|}
\hline Objek $(\mathrm{Y})$ & Wanita dengan dua temannya. \\
\hline Interpretan $(\mathrm{X}=\mathrm{Y})$ & Kecantikan wanita sempurna datang dari hati lahir dan batin. \\
\hline Makna & $\begin{array}{l}\text { Wanita tersebut mempunyai karakter dan pribadi yang ramah ter- } \\
\text { hadap sesama. }\end{array}$ \\
\hline
\end{tabular}

Sumber: Data Primer

Objek dalam scene ada Gambar 5 adalah wanita dengan dua temannya, Interpretan $(\mathrm{X}=\mathrm{Y})$ adalah kecantikan wanita sempurna datang dari hati lahir dan batin dan maknanya adalah wanita tersebut mempunyai karakter dan pribadi yang ramah terhadap sesama.

\section{(6) Scene 6}

Pada scene ini terlihat seorang wanita memakai jilbab sedang merasakan ketidaknyamanan di balik jilbabnya.

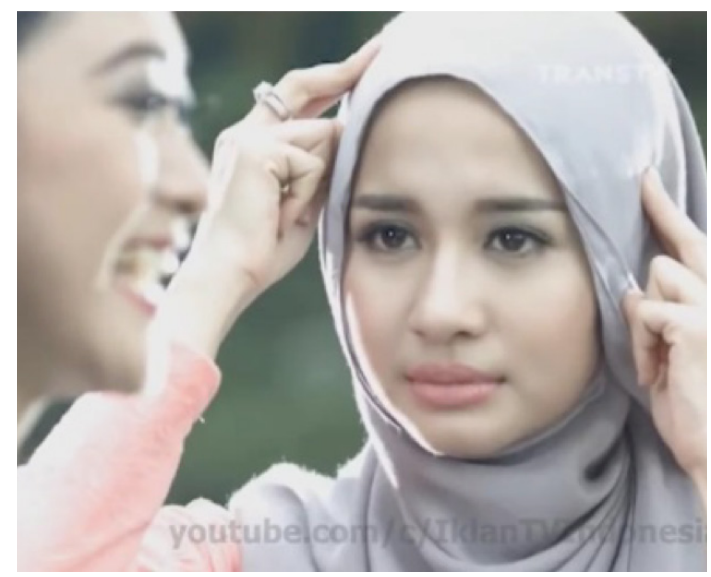

GAMBAR 6. Seorang Wanita Berhijab Memegang Kepala
Ketidaknyamanan wanita pada scene ini karena ia menggunakan jilbab sepanjang hari. Tayangan ini diperkuat dengan wajah wanita yang memakai jilbab tersebut terlihat sangat merasakan ketidak nyamanan dengan rambut yang ada di balik jilbab yang ia gunakan. Wajahnya tidak lagi menampakkan senyuman, kedua tangannya terlihat sedang memegang kepalanya. Karena itu apabila rambut tertutup terus akan berkeringat.

Berdasarkan Tabel 7, representamen (X) ikon adalah wanita berhijab dengan tangan terangkat ke kepala dan wajah seorang temannya yang sedang tersenyum. Indeks digambarkan dengan adegan seorang wanita tersebut menunjukkan bahwa ia sedang merasakan gatal dan tidak nyaman di kepalanya. Sedangkan simbolnya adalah suara narator "rambut menjadi berminyak".

Objek dalam scene pada Gambar 6 adalah wanita berhijab dengan tangan terangkat ke kepala. Interpretan $(\mathrm{X}=\mathrm{Y})$ adalah keindahan rambut harus tetap terjaga meskipun tertutup hijab sepanjang hari dan maknanya adalah merawat 
TABEL 7. Wanita Berhijab dengan Kedua Tangan di Kepala

\begin{tabular}{|l|l|}
\hline \multicolumn{1}{|c|}{ Tipe Tanda } & \multicolumn{1}{c|}{ Data } \\
\hline $\begin{array}{l}\text { Representamen }(\mathrm{X}) \\
\text { Ikon }\end{array}$ & $\begin{array}{l}\text { Wanita berhijab dengan tangan terangkat ke kepala dan wajah } \\
\text { seorang temannya yang sedang tersenyum. }\end{array}$ \\
\hline Indeks & $\begin{array}{l}\text { Adegan seorang wanita tersebut menunjukkan bahwa ia sedang } \\
\text { merasakan gatal dan tidak nyaman di kepalanya yang tertutup } \\
\text { jilbab. }\end{array}$ \\
\hline Simbol & $\begin{array}{l}\text { Suara narator "rambut menjadi berminyak" } \\
\text { Menggambarkan bahwa rambut berminyak sangat } \\
\text { jilbab. }\end{array}$ \\
\hline
\end{tabular}

TABEL 7.1 Makna Wanita Berhijab dengan Kedua Tangan di Kepala

\begin{tabular}{|l|l|}
\hline Objek $(\mathrm{Y})$ & Wanita berhijab dengan tangan terangkat ke kepala. \\
\hline Interpretan $(\mathrm{X}=\mathrm{Y})$ & $\begin{array}{l}\text { Keindahan rambut harus tetap terjaga meskipun tertutup hijab } \\
\text { sepanjang hari. }\end{array}$ \\
\hline Makna & $\begin{array}{l}\text { Merawat rambut yang tertutup hijab sangatlah sulit karena rambut } \\
\text { karena rambut akan lembab. }\end{array}$ \\
\hline
\end{tabular}

Sumber: Data Primer

rambut yang tertutup hijab sangatlah sulit karena rambut karena rambut akan lembab.

\section{(7) Scene 7}

Pada scene ini seorang wanita berhijab mencoba berusaha tersenyum, meskipun wanita tersebut sedang merasakan sesuatu yang tidak nyaman. Adegan ini diperkuat dengan wajah wanita yang berhijab tersebut tersenyum hanya untuk menghargai temannya

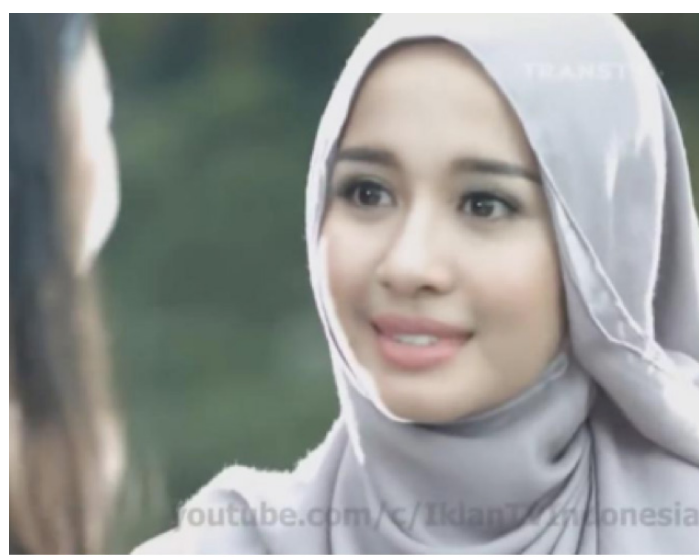

GAMBAR 7. Wanita Berhijab Berusaha Tersenyum pada Temannya sedang berbicara. Ia hanya ingin terlihat seperti tidak ada masalah atau apapun yang ia rasakan.

Wanita tersebut sangat peduli dengan perasaan temannya meskipun ia tidak memperhatikan apa yang dibicarakan oleh temannya karena ia sedang mempunyai masalah pada rambutnya. Tatapan mata wanita tersebut sangatlah terlihat seperti sedang menahan sesuatu yang tidak enak. Matanya seperti tatapan yang tidak ada arti. Wanita tersebut seperti memperhatikan pembicaraan temannya tetapi sebenarnya pikiran dan perasaannya sedang bermasalah dengan jilbab yang mulai terasa tidak nyaman.

Berdasarkan Tabel 8, representamen (X) ikon adalah seorang wanita berjilbab dan rambut seorang wanita di hadapannya. Indeks digambarkan dengan adegan seorang wanita berhijab sedang menyembunyikan sesuatu di hadapan temannya. Sedangkan simbolnya adalah wanita yang menggunakan jilbab berwarna abu-abu.

Objek pada scene pada gambar 7 adalah wanita berjilbab abu-abu. 
Alfia Zain, dkk. Makna Pemanfaatan Hijab dalam Iklan Produk Shampo...

TABEL 8. Wanita Berhijab Berusaha Tersenyum

\begin{tabular}{|l|l|}
\hline \multicolumn{1}{|c|}{ Tipe Tanda } & \multicolumn{1}{c|}{ Data } \\
\hline $\begin{array}{l}\text { Representamen }(\mathrm{X}) \\
\text { Ikon }\end{array}$ & $\begin{array}{l}\text { Seorang wanita berjilbab abu-abu dan terlihat rambut seorang teman } \\
\text { wanita tersebut yang berada tepat di hadapan wanita berjilbab itu. }\end{array}$ \\
\hline Indeks & $\begin{array}{l}\text { Adegan seorang wanita berhijab sedang menyembunyikan sesuatu } \\
\text { dihadapan temannya dan berusaha tersenyum. }\end{array}$ \\
\hline Simbol & Wanita yang menggunakan jilbab berwarna abu-abu. \\
\hline
\end{tabular}

TABEL 8.1 Makna Wanita Berhijab Berusaha Tersenyum

\begin{tabular}{|l|l|}
\hline Objek $(\mathrm{Y})$ & Wanita berjilbab abu-abu. \\
\hline Interpretan $(\mathrm{X}=\mathrm{Y})$ & $\begin{array}{l}\text { Keindahan rambut harus tetap terjaga meskipun tertutup hijab sepanjang } \\
\text { hari agar rambut yang tertutup hijab tidak mudah berkeringat dan } \\
\text { berminyak. }\end{array}$ \\
\hline Makna & $\begin{array}{l}\text { Gambaran wanita berhijab dengan wajah dan sedikit senyuman yang } \\
\text { menahan rambut yang mulai berminyak. }\end{array}$ \\
\hline
\end{tabular}

Sumber: Data Primer

Interpretan $(\mathrm{X}=\mathrm{Y})$ adalah keindahan rambut harus tetap terjaga meskipun tertutup hijab sepanjang hari. Maknanya adalah wanita berhijab dengan wajah dan sedikit senyuman yang menahan rambut yang mulai berminyak.

\section{(8) Scene 8}

Pada scene ini seorang wanita berjilbab sedang berada di lift. Terdapat seorang laki-laki dan empat orang wanita yang berada tepat di depan, di samping, dan di belakang wanita berjilbab tersebut. Wanita bejilbab ini masih tetap tersenyum sambil masih menahan rambut yang

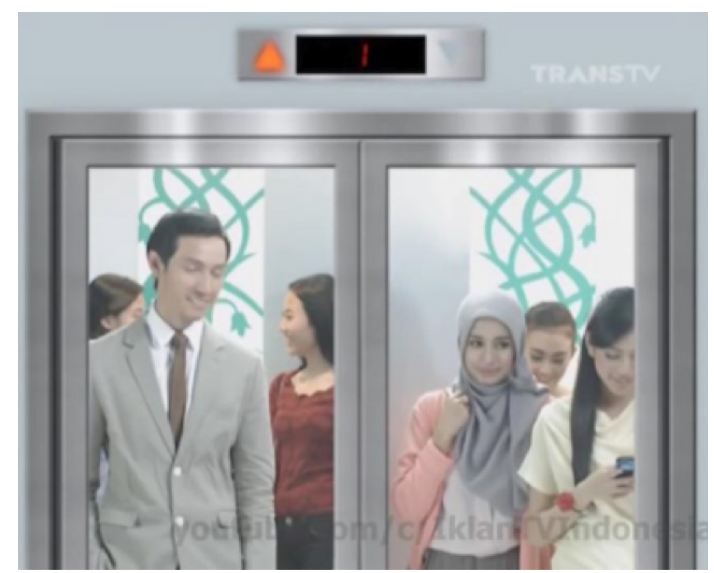

GAMBAR 8. Wanita Berjilbab Berada dalam Sebuah Lift berkeringat dan berminyak akibat aktivitas yang ia lakukan sepanjang hari. Adegan ini diperkuat dengan wajah wanita berjilbab ini tersenyum hanya sedikit, kepalanya menunduk dan agak serong ke kiri. Ia terkesan sangat malu kalau orang di sekelilingnya sadar bahwa ia sedang merasakan rambut berkeringat, berminyak, dan mulai lepek di balik jilbab yang ia gunakan tersebut. Oleh karena itu, ia berusaha menutupi wajahnya dengan cara menundukkan kepalanya agar tidak terlalu terlihat.

Berdasarkan Tabel 9, reresentamen (X) ikon adalah wanita berhijab, 1 lakilaki dan 4 wanita tidak berjilbab. Indeks digambarkan dengan seorang wanita berjilbab menundukkan kepala sambil sedikit tersenyum. Simbolnya adalah Suara narrator "kulit kepala terasa gatal".

Objek pada scene pada gambar 8 adalah wanita berjilbab berada di sebuah lift. Interpretan $(\mathrm{X}=\mathrm{Y})$ adalah kulit kepala yang terasa gatal sangatlah mengganggu aktivitas dan maknanya adalah wanita tersebut menyembunyikan kulit kepala yang sangat gatal karena tertutup jilbab sepanjang hari.

\section{(9) Scene 9}


TABEL 9. Wanita Berjilbab di Dalam Lift

\begin{tabular}{|l|l|}
\hline \multicolumn{1}{|c|}{ Tipe Tanda } & \multicolumn{1}{c|}{ Data } \\
\hline $\begin{array}{l}\text { Representamen (X) } \\
\text { Ikon }\end{array}$ & $\begin{array}{l}\text { Terdapat 6 ikon yang ada di sebuah lift, yaitu wanita berhijab, 1 } \\
\text { laki-laki dan 4 wanita tidak berjilbab. }\end{array}$ \\
\hline Indeks & $\begin{array}{l}\text { Seorang wanita berjilbab menundukkan kepala agak menengok ke } \\
\text { sebelah kirinya sambil sedikit tersenyum. }\end{array}$ \\
\hline Simbol & $\begin{array}{l}\text { Suara narator "kulit kepala terasa gatal" } \\
\text { Menggambarkan bahwa gatal disebabkan karena kulit kepala } \\
\text { tertutup sepanjang hari. }\end{array}$ \\
\hline
\end{tabular}

TABEL 9.1 Makna Wanita Berjilbab di Dalam Lift

\begin{tabular}{|l|l|}
\hline Objek $(\mathrm{Y})$ & Wanita berjilbab berada di sebuah lift \\
\hline Interpretan $(\mathrm{X}=\mathrm{Y})$ & Kulit kepala yang terasa gatal sangatlah mengganggu aktivitas \\
\hline Makna & $\begin{array}{l}\text { Gambaran wanita berhijab dengan wajah dan sedikit senyuman } \\
\text { dengan kepala yang menunduk menandakan bahwa wanita tersebut } \\
\text { menyembunyikan kulit kepala yang sangat gatal karena tertutup jilbab } \\
\text { sepanjang hari. }\end{array}$ \\
\hline
\end{tabular}

Sumber: Data Primer

Pada scene ini terlihat tulisan yang ada pada produk shampo tulisan berwarna putih dengan wadahnya berwarna hijau. Tayangan ini ingin memperkenalkan nama sekaligus meyakinkan masyarakat akan produk shampo dengan pengambilan gambar close-up pada tulisan pada wadah shampo tersebut, menjelaskan bahwa shampo ini sangat aman dan cocok digunakan oleh wanita Indonesia yang mayoritas penduduknya beragama Islam,

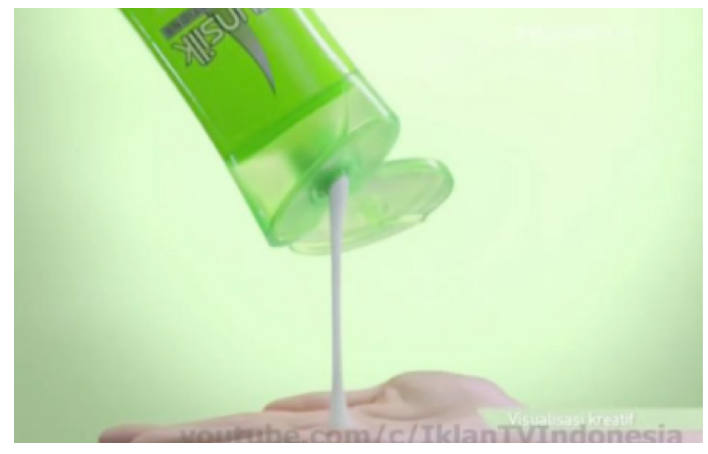

GAMBAR 9. Tulisan Merk Produk Shampo

TABEL 10. Tulisan Merk Shampo

\begin{tabular}{|l|l|}
\hline Tipe Tanda & \multicolumn{1}{|c|}{ Data } \\
\hline $\begin{array}{l}\text { Representamen }(\mathrm{X}) \\
\text { Ikon }\end{array}$ & $\begin{array}{l}\text { Sebuah botol shampo dengan tulisan berwarna putih serta background } \\
\text { berwarna hijau dilengkapi dengan formula yang terkandung. }\end{array}$ \\
\hline Indeks & $\begin{array}{l}\text { Tulisan yang digunakan sebagai merk pada produk shampo, menjadi } \\
\text { tanda bahwa produk tersebut siap bersaing di pasaran. }\end{array}$ \\
\hline Simbol & $\begin{array}{l}\text { Suara narator "dengan sunsilk saya mengkreasikan Sunsilk clean and } \\
\text { fresh dengan vitamin citrus complex efektif menghilangkan keringat } \\
\text { dan menjaga rambutmu tetap bersih dan segar." }\end{array}$ \\
\hline
\end{tabular}

TABEL 10.1 Makna Tulisan Merk Shampo

\begin{tabular}{|l|l|}
\hline Objek $(\mathrm{Y})$ & Merk produk shampo \\
\hline Interpretan $(\mathrm{X}=\mathrm{Y})$ & Produk shampo yang terbuat dari bahan citrus complex. \\
\hline Makna & $\begin{array}{l}\text { Produk yang telah lama diproduksi yang kini diinovasi akan } \\
\text { menjadikan rambut tetap terlihat indah. }\end{array}$ \\
\hline
\end{tabular}

Sumber: Data Primer 
selain itu juga cocok digunakan oleh siapa pun yang beragama non muslim.

Keamanannya sangat teruji secara laboratorium, hal tersebut ditegaskan dengan suara narator yang mengatakan "dengan Sunsilk saya mengkreasikan Sunsilk clean and fresh dengan vitamin citrus complex efektif menghilangkan keringat dan menjaga rambutmu tetap bersih dan segar". Maksud potongan kalimat tersebut adalah bahan yang digunakan dalam pembuatan produk shampo ini murni berasal dari alam, sehingga sangat aman untuk kulit kepada dan dapat menciptakan sensasi kesegaran dan kenyamanan saat memakai hijab atau pakaian tertutup.

Berdasarkan Tabel 10, representamen $(\mathrm{X})$ ikon adalah sebuah botol shampo dengan tulisan berwarna putih. Indeks digambarkan dengan tulisan yang digunakan sebagai merk pada produk shampo. Simbolnya adalah suara narrator "dengan Sunsilk saya mengkreasikan Sunsilk clean and fresh dengan vitamin citrus complex efektif menghilangkan keringat dan menjaga rambutmu tetap bersih dan segar."

Objek dalam scene pada Gambar 9 adalah merk produk shampo. Interpretan $(\mathrm{X}=\mathrm{Y})$ adalah produk shampo yang terbuat dari bahan citrus complex. Maknanya adalah produk yang telah lama diproduksi yang kini diinovasi akan menjadikan rambut tetap terlihat indah.

\section{(10) Scene 10}

Pada scene ini seorang wanita berkerudung sedang tersenyum dengan mata berbinar-binar yang terlihat dari depan, dengan kepala agak menengok ke samping kiri disertakan background taman yang indah. Demikian ekspresi wajah dengan mata yang berbinar-binar serta senyum yang mengembang hampir sempurna, menandakan kebahagiaan seutuhnya yang tanpa dibuat-buat.

Kemudiandalamscene ini, potongan kalimat yang diucapkan oleh sang narator adalah "rambut dan kulit kepalaku terasa bersih dan segar sepanjang hari". Tampil sempurna dengan kesegaran rambut merupakan dambaan setiap wanita untuk menambah percaya diri ketika berada di

TABEL 11. Wanita Tersenyum dengan Mata Berbinar

\begin{tabular}{|l|l|}
\hline \multicolumn{1}{|c|}{ Tipe Tanda } & \multicolumn{1}{c|}{ Data } \\
\hline $\begin{array}{l}\text { Representamen }(\mathrm{X}) \\
\text { Ikon }\end{array}$ & $\begin{array}{l}\text { Seorang wanita yang mengenakan jilbab sedang tersenyum } \\
\text { dengan mata berbinar-binar dengan background taman yang } \\
\text { indah }\end{array}$ \\
\hline Indeks & $\begin{array}{l}\text { Wanita dengan busana Muslimah dengan jilbab hijau yang } \\
\text { menandakan bahwa dia merasakan kesegaran yang ada di kulit } \\
\text { kepalanya yang telah menggunakan shampo. }\end{array}$ \\
\hline Simbol & $\begin{array}{l}\text { Suara narator "rambut dan kulit kepala ku terasa bersih dan segar } \\
\text { sepanjang hari", ini menjadi gambaran kindahan dan kenyamanan } \\
\text { rambut dan kulit kepala yang seimbang. }\end{array}$ \\
\hline
\end{tabular}

TABEL 11.1 Makna Wanita Tersenyum dengan Mata Berbinar

\begin{tabular}{|l|l|}
\hline Objek $(\mathrm{Y})$ & Seorang wanita berbusana Muslimah \\
\hline Interpretan $(\mathrm{X}=\mathrm{Y})$ & $\begin{array}{l}\text { Kesehatan dan kenyamanan tidak hanya bisa dilihat dari satu sisi } \\
\text { saja }\end{array}$ \\
\hline Makna & $\begin{array}{l}\text { Menggambarkan kecantikan dan penampilan yang seimbang } \\
\text { dengan memperhatikan kenyamanan. }\end{array}$ \\
\hline
\end{tabular}

Sumber: Data Primer 


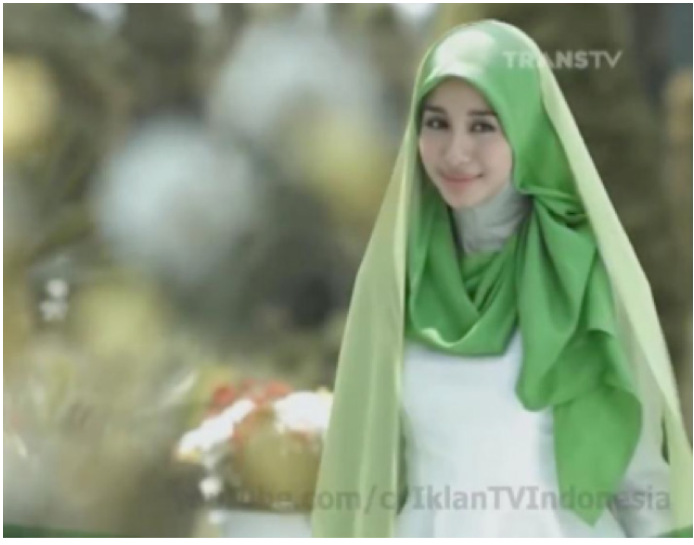

GAMBAR 10. Seorang Wanita Sedang Tersenyum dengan Mata Berbinar-binar

keramaian dan tidak merasakan rambut lepek dan gatal yang sangat mengganggu aktivitas.

Berdasarkan Tabel 11, representamen $(\mathrm{X})$ ikon adalah wanita yang mengenakan jilbab sedang tersenyum dengan mata berbinar-binar. Indeks digambarkan dengan wanita yang merasakan kesegaran di kulit kepalanya. Simbolnya adalah suara narator "rambut dan kulit kepalaku terasa bersih dan segar sepanjang hari."

Objek dalam scene pada Gambar 10 adalah seorang wanita berbusana Muslimah. Interpretan (X=Y) adalah kesehatan dan kenyamanan tidak hanya bisa dilihat dari satu sisi saja. Maknanya adalah kecantikan yang digambarkan dengan memperhatikan kenyamanan.

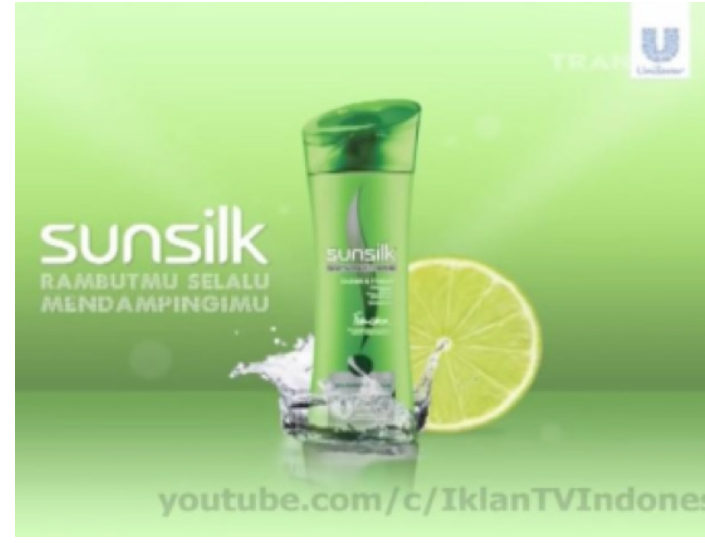

GAMBAR 11. Jenis Produk Shampo Sunsilk Clean And Fresh

\section{(11) Scene 11}

Pada scene ini terlihat tulisan dan botol shampo berwarna hijau dengan background hijau dan wadah shampo berwarna hijau dengan buah lemon yang ada di belakang botol shampo serta dilengkapi dengan nama perusahaan di pojok kanan gambar.

Tayangan ini memperkenalkan bahwa produk shampo tersebut diproduksi oleh salah satu perusahaa besar di Indonesia yang akan dipasarkan khusus untuk kaum hawa, dengan memajang wadah shampo tersebut. Selanjutnya diperkuat dengan suara sang narator "sunsilk clean and fresh". Sang narator berusaha menjelaskan produk shampo tersebut kepada masyarakat agar rambut terasa lebih segar sepanjang hari

TABEL 12. Produk Shampo Sunsilk Clean And Fresh

\begin{tabular}{|l|l|}
\hline Tipe Tanda & \multicolumn{1}{|c|}{ Data } \\
\hline $\begin{array}{l}\text { Representamen }(\mathrm{X}) \\
\text { Ikon }\end{array}$ & Sebuah botol shampo lengkap dengan merk dan logo perusahaan \\
\hline Indeks & $\begin{array}{l}\text { Botol shampo berwarna hijau dengan tulisan merk berwarna } \\
\text { putih }\end{array}$ \\
\hline Simbol & Suara narator "sunsilk clean and fresh" \\
\hline
\end{tabular}

TABEL 12.1 Makna Produk Shampo Sunsilk Clean And Fresh

\begin{tabular}{|l|l|}
\hline Objek $(\mathrm{Y})$ & Produk shampo \\
\hline Interpretan $(\mathrm{X}=\mathrm{Y})$ & Produk shampo yang dibuat khusus untuk wanita berhijab \\
\hline Makna & $\begin{array}{l}\text { Keindahan dan kesegaran rambut akan menjadikan seseorang } \\
\text { menjadi lebih nyaman }\end{array}$ \\
\hline
\end{tabular}

Sumber: Data Primer 
terutama untuk para kaum wanita yang menggunakan hijab.

Berdasarkan Tabel 12, representamen (X) ikon adalah botol shampo lengkap dengan merk dan logo perusahaan. indeks digambarkan dengan botol shampo berwarna hijau. Simbolnya adalah suara narator "sunsilk clean and fresh".

Objek dalam scene pada Gambar 11 adalah produk shampo. Interpretan $(\mathrm{X}=\mathrm{Y})$ adalah shampo yang dibuat khusus untuk wanita berhijab. Maknanya adalah keindahan dan kesegaran rambut akan menjadikan seseorang menjadi lebih nyaman.

\section{Interpretasi Penelitian}

Iklan shampo Sunsilk Clean And Fresh yang diperankan seorang model menggunakan busana Muslimah lengkap dengan kerudung ini merupakan iklan yang dibuat untuk memperkenalkan produk shampo versi berjilbab terbaru yang dikeluarkan oleh PT Unilever, Tbk. Iklan yang memiliki jalan cerita dengan durasi 30 detik ini menampilkan sosok seorang wanita cantik yang menggunakan busana Muslimah, namun masih terlihat ceria dan anggun serta mempesona.

Dalamiklanini, sosok waita tersebut menggunakan busana tertutup lengkap dengan jilbabnya dengan model jilbab masa kini dan tidak berdasarkan syariat Islam karena masih memperlihatkan lekuk tubuh. Menurut Ibn Asyur, model jilbab bisa bermacam-macam sesuai perbedaan keadaan (selera) wanita dan diarahkan oleh adat kebiasaan (Shihab, 2002).

Tempat yang digunakan model wanita dalam iklan adalah sebuah ruangan, sebuah taman, sebuah café, dan di dalam lift. Dalam iklan ini, peneliti menemukan bahwa kalimat pernyataan yang diucapkan menggambarkan seorang wanita seutuhnya, menginginkan kenyamanan dan kesegaran walaupun dalam berbagai aktivitas sehari-hari yang ia jalani, tanpa adanya gangguan yang dirasakan tidak nyaman pada kulit kepala dan rambut yang akan sangat mengganggu aktivitas mereka sepanjang hari.

Kemudian, dalam scene ditampilkan gambar bertuliskan merk yang diperbesar, dengan tujuan untuk memperkenalkan shampo dengan inovasi baru yang akan ditujukan untuk wanita Muslimah dalam menunjang kepercayaan dirinya agar tetap terlihat segar dan ceria secara fisik ketika sedang melakukan aktivitas di luar rumah tanpa harus merasa takut akan keamanan dari produk shampo tersebut. Hal ini diperkuat dengan pernyataan narator yang mengatakan bahwa "dengan Sunsilk saya mengkreasikan Sunsilk clean and fresh dengan vitamin citrus complex efektif menghilangkan keringat dan menjaga rambutmu tetap bersih dan segar".

Keindahan rambut menjadi hal yang utama bagi seorang wanita dalam menumbuhkan rasa percaya diri ketika berada di lingkungan luar. Seperti penggalan kalimat yang diucapkan sang narator "rambut dan kulit kepalaku terasa bersih dan segar sepanjang hari". Dengan potongan kalimat tersebut, Sunsilk Clean and Fresh ingin meyakinkan masyarakat khususnya wanita untuk tetap menjaga kebersihan rambut dengan menggunakan produk shampo yang telah terjamin mutu dan kualitasnya ini. Karena Sunsilk Clean and Fresh hadir untuk menjadikan kecantikan seorang wanita. Sunsilk percaya bahwa kepercayaan diri adalah kunci dari keberhasilan, karena jika kulit kepala terasa gatal dan tidak nyaman karena keringat berlebih, akan memengaruhi rasa percaya diri dan menjadi sebuah halangan dalam berkarya.

Sunsilk bekerjasama dengan Fransesca Fusco menciptakan shampo dengan Citrus Complex untuk memberikan sensasi bersih dan segar pada kulit kepala, sehingga Muslimah 
bebas beraktifitas dan tetap percaya diri dalam berkarya dan mewujudkan mimpi (Putri, 2015).

Iklan ini adalah jenis iklan komersial yang mempromosikan produk shampo dengan model berhijab dalam bentuk tayangan gambar dan narasi di dalam iklan untuk meyakinkan masyarakat untuk mempercayai bahwa prosuk shampo tersebut aman dan nyaman apabila digunakan terlebih lagi untuk wanita berjilbab. Dalam iklan ini hanyalah mencari keuntungan dan bagaimana iklan tersebut oleh masyarakat agar produk yang mereka keluarkan laku di pasaran (Piliang, 2009).

\section{SIMPULAN}

Dari hasil temuan dan pembahasan tentang pemanfaatan hijab dalam iklan produk shampo Sunsilk Clean and Fresh versi berjilbab di televisi, dapat disimpulkan bahwa iklan ini menggunakan berbagai tanda mulai dari representamen objek dan interpretan. Ikon yang sering dimunculkan adalah ikon seorang wanita menggunakan hijab dengan model yang sedang tren bukan berdasarkan syariat Islam.

Iklan ini menunjukkan bahwa iklan tersebut hanyalah jenis iklan komersial seperti pada umumnya, produsen mencari keuntungan melalui iklan tersebut dengan menggunakan model berjilbab untuk mempekenalkan produk shampo yang sebenarnya sudah ada dari tahun 2004 hanya saja dalam bentuk kemasan terbaru. Dapat dikatakan bahwa iklan tersebut sangat memanfaatkan tren hijab yang sekarang sedang pesat. Maka itu, produsen pembuat shampo tersebut membuat produk yang menarik simpati masyarakat, terutama kalangan wanita Muslimah yang sekarang banyak menggunakan busana tertutup dan berhijab.
Terlihat jelas bahwa apabila seorang Muslimah menggunakan hijab karena ia benar-benar menjalankan ibadah kepada Allah Swt, ia akan menemukan kenyamanan terhadap pakaian yang digunakan meskipun keadaan kepala tertutup sepanjang hari.

\section{DAFTAR PUSTAKA}

Ahmadi, D. \& Yohana, N. (2005). Konstruksi Jilbab sebagai Bentuk Keislaman. Jurnal Mediator. 8(2). Hal 235-248.

Jayanti, E. D. (2014). Eksploitasi Hijab Dalam Iklan Produk Muslimah Kosmetik Sophie Paris di Televisi. Jakarta: Univeritas Islam Negeri.

Khairiyah, S. N. (2013). Analisis Produksi terhadap Program Sinetron Tukang Bubur Naik Haji The Series (episode 492 dan 493). Jakarta: Universitas Islam Negeri.

Kriyanto, R. (2007). Teknis Praktis Riset Komunikasi. Jakarta: Prenada Media Group.

Moloeng, L. J. (2005). Metodologi Penelitian Kualitatif. Bandung: Remaja Rosda Karya.

Piliang, Y. A. (2009). Semiotika Komunikasi Visual. Yogyakarta: Jalasutra.

Shihab, M. Q. (2002). Tafsir Al-Misbah: Pesan, Kesan dan Keserasian AlQur'an. Vol-9. Jakarta: Lentera Hati.

Sobur, A. (2009). Semiotika Komunikasi. Bandung: Remaja Rosda Karya.

Suryawati, I. (2011). Jurnalistik: Suatu Pengantar Teori dan Praktik. Bogor: Ghalia Indonesia.

Synnott, A. (2007). Tubuh Sosial: Simbolisme, Diri, dan Masyarakat. Yogyakarta: Jalasutra.

Verdiansyah, D. (2008). Filsafat Ilmu Komunikasi: Suatu Pengantar. cet. Ke2. Jakarta: Indeks.

Wibowo, I.S.W. (2013). Semiotika Komunikasi: Aplikasi Praktis bagi Penelitian dan Skripsi Komunikasi. Cet ke-2. Jakarta: Mitra Wacana Media. 